\title{
The Dynamics of the Xylophones in Cameroon Grassfields Arts
}

\author{
Exodus Tikere Moffor ${ }^{1^{*}}$

${ }^{\mathrm{T}}(\mathrm{Ph} . \mathrm{D})$, The University of Yaoundé 1 , Cameroon

Article History

Received: 09.11.2020

Accepted: 21.11.2020

Published: 17.03.2021

Journal homepage: https://www.easpublisher.com

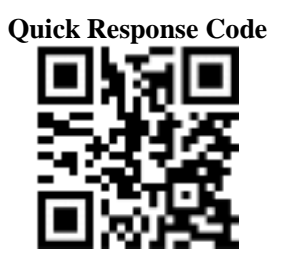

Abstract: Every society has the interest to preserve its cultural heritage for posterity. The xylophone which is one of the prominent instruments used to produce music in the Grassfields of Cameroon is an important heritage of this people. It is used in most traditional dances both sacred and profane. This instrument has undergone transformation and is still being transformed. Although the history of the xylophone is difficult to trace, it has evolved from simple bars made from special wood placed on bananas or plantain stems to complex, well carved bars and built in boxes and others on long wooden logs. The production and manipulation of this musical instrument was reserved for the nobility who had the prerogative to own masquerades "jujus." This knowledge was usually transmitted from father to son(s) after so many years of apprenticeship. Today, the ownership of the juju is open to all and due to this reason; the sacredness of this invaluable object is slowly dying out. The production of xylophones is done with any available wood with many of them built to match changing times. This paper explores how the xylophone has evolved over time in the Grassfields of Cameroon and the significance of the xylophone in the culture of the Grassfielders. With information got from participation in traditional dances in which the xylophones are used and interviews with notables and juju owners, I found out that the production of xylophones used to be a part of most royal settings because demonstrated the political, social and religious organisation of Grassfields kingdoms. These xylophones gradually became a major musical instrument in some Christian churches.

Keywords: Tradition, xylophone, Grassfields, dynamics, juju, cultural heritage.

Copyright ( $\odot 2021$ The Author(s): This is an open-access article distributed under the terms of the Creative Commons Attribution 4.0 International License (CC BY-NC 4.0) which permits unrestricted use, distribution, and reproduction in any medium for non-commercial use provided the original author and source are credited.

\section{INTRODUCTION}

The xylophone is a wonderful instrument. It has a rich history, dating from the 9th century and being developed independently in both Africa and Asia. It enjoys widespread use in everything from traditional African tribal music to an American elementary school classroom, where it is used to teach introductory music principles to children. The xylophone (from the Greek word - xylon, "wood" and phonē, "sound, voice", meaning "wooden sound") is a musical instrument in the percussion family that consists of wooden bars struck by mallets. Each bar is an idiophone tuned to a pitch of a musical scale, whether pentatonic or heptatonic in the case of many African and Asian instruments, diatonic in many western children's instruments, or chromatic for orchestral use. The term may be used generally, to include all such instruments, such as the marimba and balafon or, more specifically, to refer to an orchestral instrument of somewhat higher pitch range than the chromatic marimba. It is sometimes mistakenly used to refer to the similar lithophone and metallophone, instruments of the glockenspiel or pixiphone type [1].

In the Grassfields of Cameroon, this musical instrument is made from different types of wood which are in a variety of sizes, shapes and lengths.
Xylophones are only in the compounds of owners of traditional dance groups who either produce them by themselves or ask someone else to produce under their supervision. Their production therefore is done following the rhythm of the dance group. This musical instrument is used fundamentally to produce folk music for the traditional dance groups. The Catholic church which forms part of the religious organisations which use the xylophones use the services of some skilful artist (wood carvers) to produce the xylophones and carpenters to build them in boxes.

The Grassfields comprise the three culture areas of the Bamenda, Bamileke and the Bamoun. They are a country of grassy hills and mountains with open gallery forests at an average altitude of 4000 feet above sea level. Situated between the equatorial forest zone to the south and the tropical savannah region to the north (at latitude $5^{\circ}$ to $6^{\circ} 30^{\prime}$ north), the distinct physical features of the Grassfields are equally determined by their transitional character and their high evaluation which accounts for the reasonably healthy climate with temperatures approximating an average of $80^{\circ} \mathrm{F}$. The natural vegetation of this area consists of tall grasses with raffia and oil palms and banana trees surrounding the compounds. The stems of the banana and plantain trees are used to support xylophones when in use. In the 
domain of religion, xylophones are used during funerals and death celebrations to produce traditional music which ushers the deceased to the world of the spirits.

In the past before contact with the external world, the xylophone was produced, owned and used by specific people and sacred societies in the cultural sphere of the Grassfields. Contact with the external world, colonisation and Christianity gave a different perspective to the xylophone, in production, ownership and use.

\section{Methodology}

Data for this paper was collected using the qualitative and quantitative methods. Underlying the qualitative methods, techniques such as participant observation, interview and life history were used. Together with questionnaires which were established for different categories of people like juju owners, producers of xylophones and religious leaders, I had information on the production of xylophones, the different tree types used for their production and how these raw materials are obtained. Through these methods, I also had information on procedure for ownership of jujus and the uses of the xylophones among the Grassfielders of Cameroon. The data was analysed as the research was going on and interpreted using the evolution and functionalist theories.

\section{FINDINGS}

This portion is reserved for the production of xylophones which comprises the techniques and procedures in xylophones production (acquisition of raw materials and tools used in xylophones fabrication), the functions of this musical instrument (in funerals, death celebrations and in education) and the modernization of the xylophone.

\section{Xylophones Production: Techniques and Procedures}

The xylophones as we have seen in the introduction are a musical instrument of the percussion family consists of wooden bars struck with mallets. To better comprehend the techniques in xylophones production, we have to understand the different tree types which are used, where and how they are obtained.

The xylophone is fabricated from wood and at its best when already dry. This object was produced in the days of old using only the umbrella tree due to its high sound quality. Important to note is the fact that the umbrella tree is a white wood which is soft and very easy to carve. But today, xylophones are produced with a variety of tree types ranging from eucalyptus to camwood. These hard woods are preferred because they can last longer and are also resistant to insect bites.

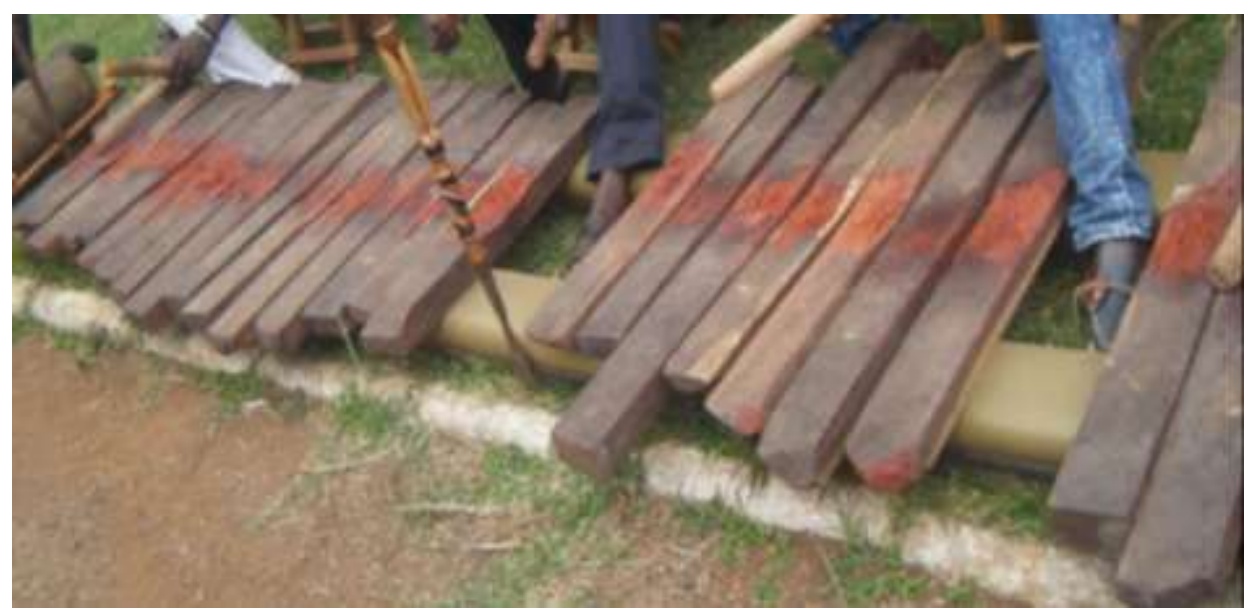

Plate-1: Xylophones made with camwood. Photo Tikere, 20/10/2019

\section{Acquisition of Wood for the Manufacture of Xylophones}

Trees like the umbrella and eucalyptus are obtained from the local forest meanwhile the camwood is got from the forest regions; centre, south, south west, and the littoral areas. Felling a tree for the production of the xylophone does not require ritual performance like felling wood for sculptural fabrication. Such trees are not found in ritual sites although they a religious functions.

\section{Techniques and Procedures in Xylophones Production}

Producers of the xylophone go through a number of stages and different tools are used at different steps of production. The first step is 
identifying the tree which has to be used. In stage two the tree is felled and cross cut into logs depending on the length of the xylophone. In the past, before the introduction of the chain saw, such trees were fell using an axe, the locally made axe (see plate below).

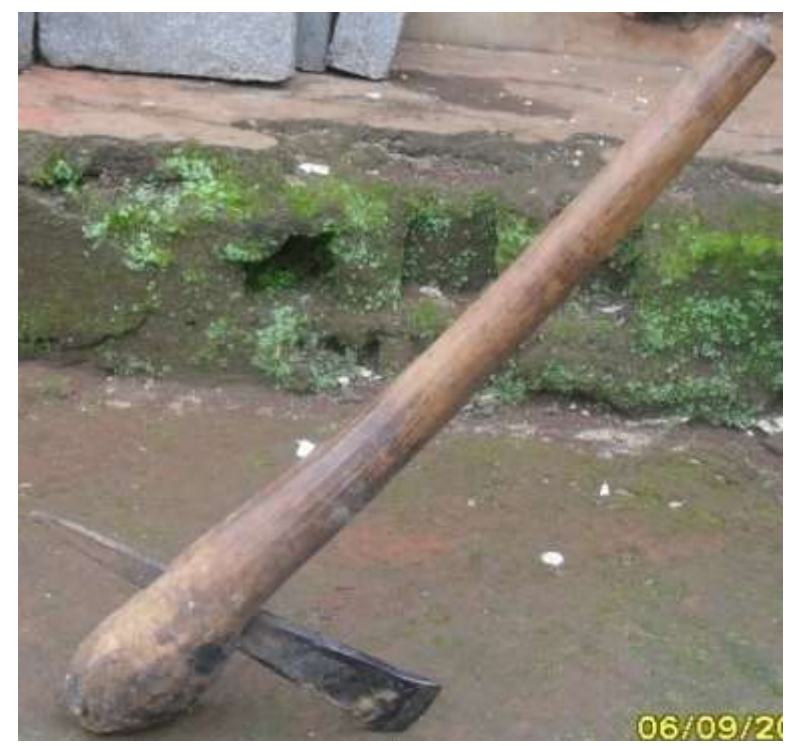

Plate-2: A native axe used for felling a tree. Photo Tikere, 11/05/2017

Today, this task is performed with the chain saw under the supervision of the producer who makes sure that the logs are cut in the prescribed dimensioned. The tree being cut below is of the umbrella tree family. It is very soft wood which is very easy to fell be it with the traditional axe or with the chain saw.

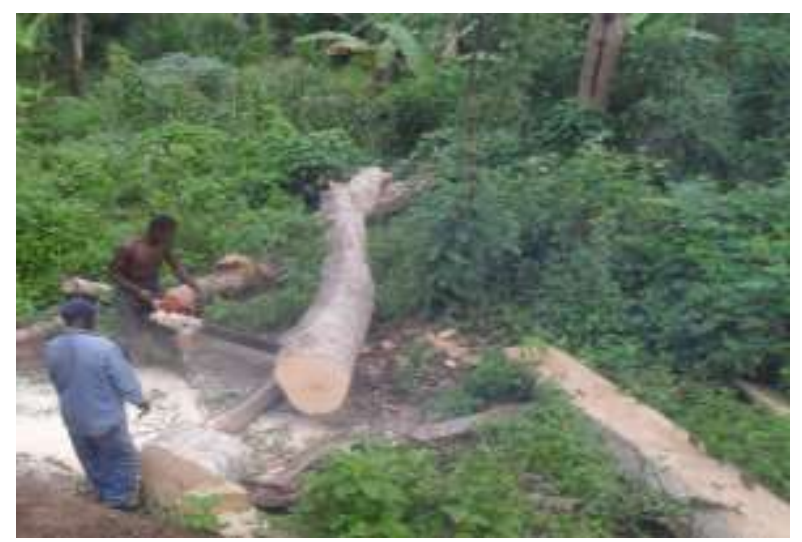

Plate-3: A tree for carving xylophones. Photo Tikere, 01/11/2018

These logs are later split into pieces each forming a bar of xylophone. This task was performed in the past with the axe (see plate 3 above). In this case, the machete is used to smoothen each bar thereby removing all the pieces which are on the bar. The machete is shaped with a file each time that it is blunt. To simplify the task, the producer may require the services of a chain saw to split the logs into bars.

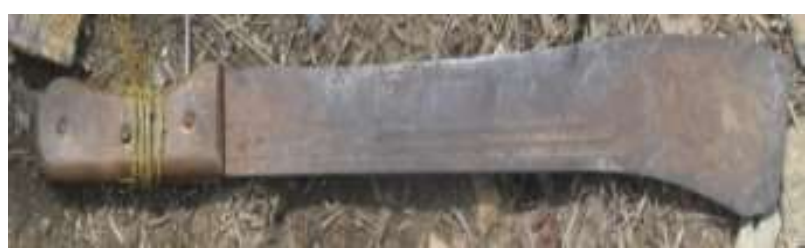

Plate-4: A machete. Photo Tikere, 11/05/2017

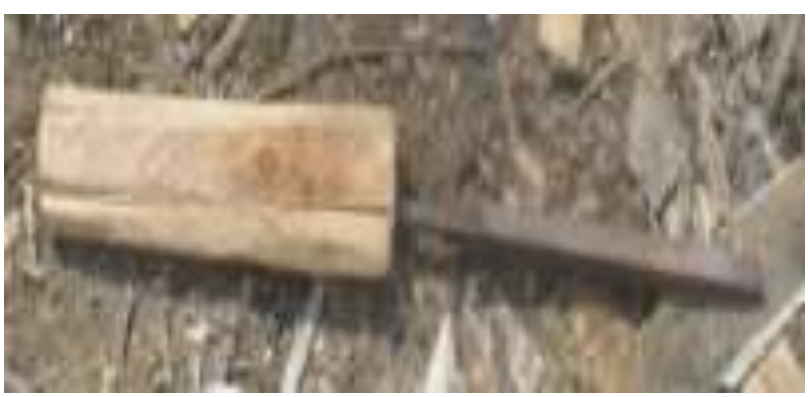

Plate-5: A file. Photo Tikere, 11/05/2017

In the third step, a cutlass is used to trim the edges of the logs and reduce the length of those that have to be short. This means that the xylophones are in lengths with corresponding sounds or pitches.

\section{The Uses of Xylophones}

The xylophone plays a very invaluable function in the lives of the Grassfields people. Together with other musical instruments (such as the drum, trumpet, rattles and guitar) it is used primarily to produce music in traditional ceremonies such as death celebration, enthronement of a new fon, and in funerals. They are also used in churches especially the Catholic and Presbyterian churches to produce music. The xylophone equally serves as didactic material in some societies especially in the west and America.

In the past, xylophones were laid on banana or plantain stems before hitting with mallets. Such plantain or bananas stems were usually harvested around the compound and transported to the field by one or two or three persons depending on the size and length of the stem. 


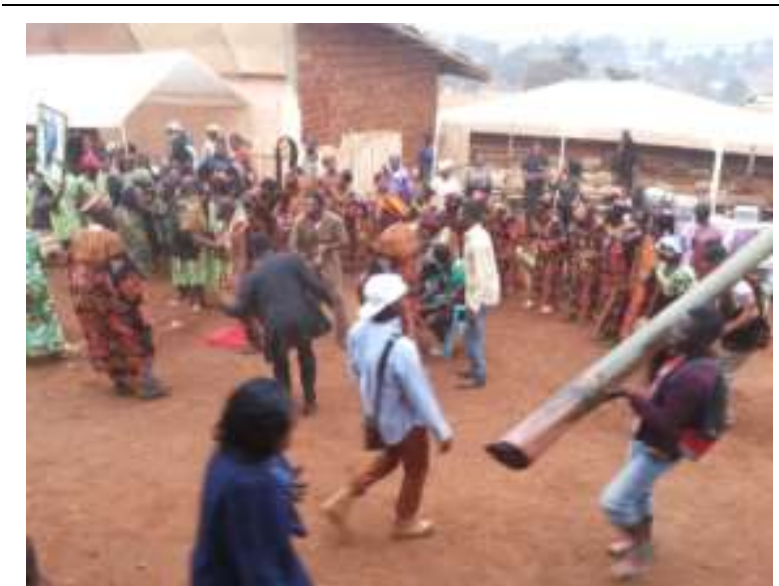

Plate-6: A boy carrying a banana stem. Photo Tikere, 11/11/2019

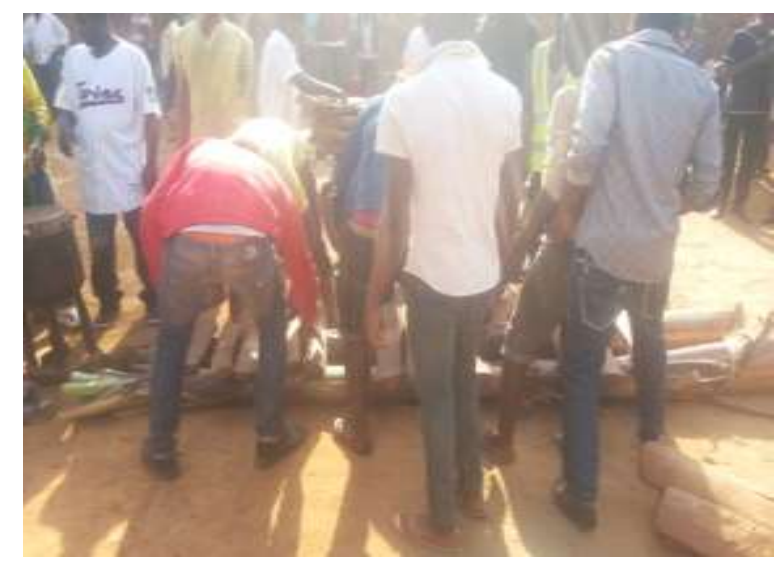

Plate-7: Xylophones laid on banana stems. Photo Tikere, 11/11/2019

When the xylophones are been used, there are two to three people to set them in order since when hit with the mallet the bars are displaced (see plate 8 below).

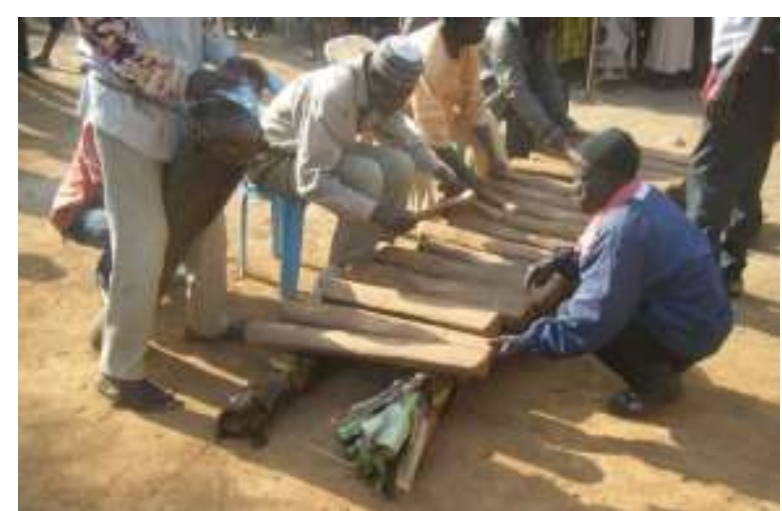

Plate-8: A man arranging xylophones. Photo Tikere, 11/11/2019
These xylophones are been transported from one place to another by members of the dance group. They could be either carried on the head or in the shoulders.

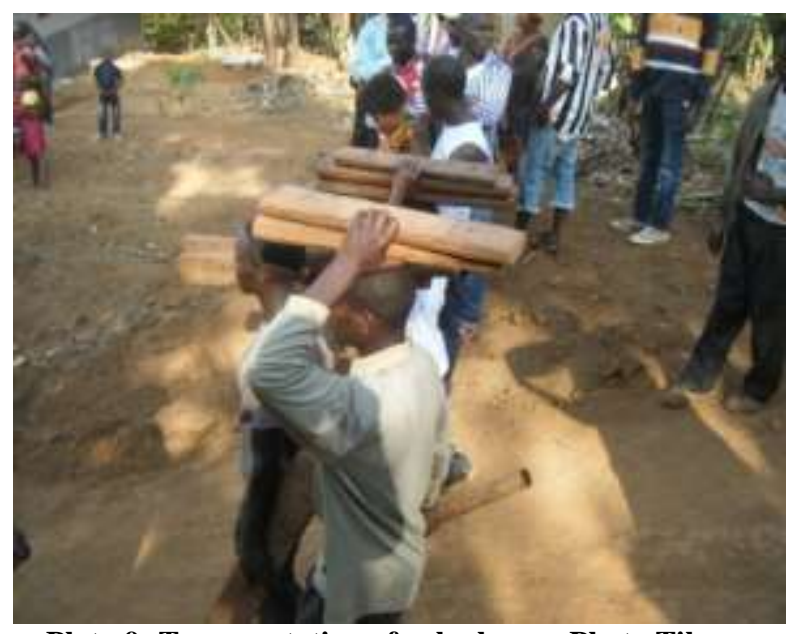

Plate-9: Transportation of xylophones. Photo Tikere, 11/11/2019

\section{The use of the xylophone in death celebrations}

The xylophone is used to produce music during death celebrations. To many people in many cultures, music is an important part of their way of life. Ancient Greek and Indian philosophers defined music as tones ordered horizontally as melodies and vertically as harmonies. 20th-century composer John Cage thought that any sound can be music, saying, for example, "There is no noise, only sound." Musicologist Jean-Jacques Nattiez summarizes the relativist, postmodern viewpoint: "The border between music and noise is always culturally defined - which implies that, even within a single society, this border does not always pass through the same place; in short, there is rarely a consensus... By all accounts there is no single and intercultural universal concept defining what music might be."

Music existed in Prehistoric times and there can be theorised based on findings from Palaeolithic archaeology sites. India has one of the oldest musical traditions in the world - references to Indian classical music (marga) are found in the Vedas, ancient scriptures of the Hindu tradition. The earliest and largest collection of prehistoric musical instruments was found in China and dates back to between 7000 and 6600 BC. The Hurrian song, found on clay tablets that date back to approximately $1400 \mathrm{BC}$, is the oldest surviving notated work of music. 


\section{Folk Music in Burials}

Most music produced during funerals and death commemoration is done using the xylophone and other musical instruments. Among the Grassfielders, funerals and death celebrations are very important social as well as religious ceremonies that many rituals are performed to reverent and venerate the departed.

Burial is the act of putting a dead body into the ground, or the ceremony connected with this. In this paper, I am going to examine two ceremonies connected with dead. The first is funeral and the second is death celebration. While funeral is the ceremony for the burying the body of a person death celebration is the final burial of the deceased. Among the Grassfields chiefdoms, funeral is a sad event because the passing away of the deceased is still fresh in the minds of the people, death celebration is the final burial of a departed person and the latter can be organised some years after the funeral ceremony.

\section{Folk Music during Funerals}

If a man dies in the Grassfields areas, from the time he/she dies to the period after burial, there are a series of music and dances that comprise part of the activities, the type of music and dance and activities depend on the status of the deceased. The funeral of a notable does not last for long. To the majority of Grassfields chiefdoms, if a notable dies, the corpse is not kept in the mortuary nor put in a coffin but it is buried within forty-eight hours. During this period pending burial, only secret masquerades to which he belonged come out to dance as well as bury him and his corpse is not viewed by all but a selected few. As a result, most of their activities including the dancing are carried out at night.

The funeral of a commoner is also characterised by some music and dance. The dances range from traditional dance (masquerades) to Christian music and dance which take place usually at night. The masquerades that take part in the funeral of commoners are all profane, they are open to the public who can join in the dancing. They use the xylophones to produce music and those who produce the music occupy a particular area meanwhile the masquerades and those who accompany the dance use a specific area.

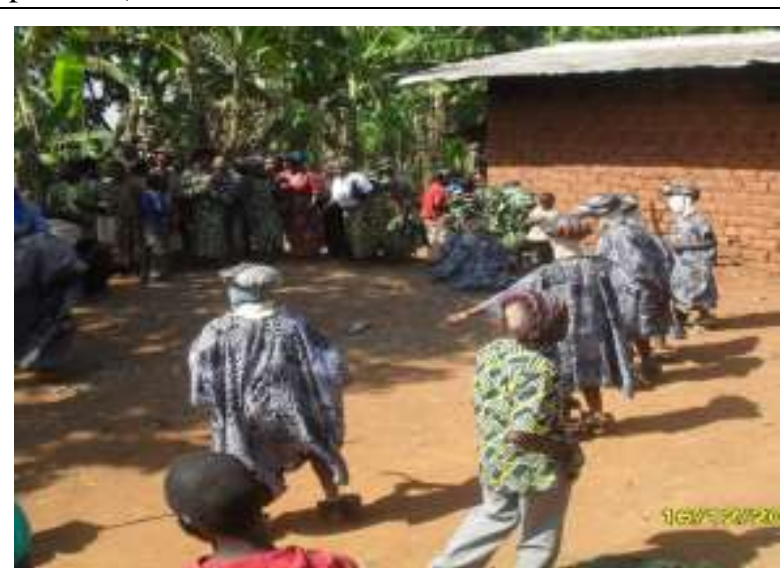

Plate-10: Masquerades and women dancing in separate corners. Photo Tikere, 11/11/2019

This music like many others show that there is life after death. The people believe that when a man dies, he goes beyond where he/she will continue to live and look after those that are still living. When the living die, they have to be ushered in the world of the ancestors and spirits by those who were there before them; the living-dead and ancestors. The latter are very instrumental according to the belief system of the Grassfields people.

The world we live in is like a stage where we come live, do what we have to do and then die. There is no one who will live on earth for ever. Some people believe that we are strangers or passers by on this earth. While Christians believe that life ends at death, traditional African religion believes that there is life after death that is, the people give respect and honour to those who have died and consider them as spirit that is why they send them to those who had died a long time ago to provide them with many good things: peace, love, prosperity, fertility and many others. Segy [2] reveals that behind the concept of 'spirits' ethnologists find a meaning: identity and personality have been given to an unknown force. Spirits were 'personalisation' of forces which the African feared and could not cope with on other levels. And once enrobed with an identity, a spirit became 'humanlike,' with needs similar to those of humans. The spirit became similar to the African, and the African was able to understand him and establish a relationship with him. One aspect of this relationship was a sacrificial ritual: the flesh or blood of an animal was offered to the spirit to feed it. Another aspect could be a gift of something precious to a spirit who had caused a misfortune to ease his malevolence or wrath. 
The African, like many other people, believed that the important transition points in life should mark the passage into different stage of life. The most important were those of birth, the beginning of puberty, marriage and death. In each of these stages, there is a celebration which involves the manifestation where people sing and dance not only for themselves but to link the living with the departed.

Death provides that great entry into the realm of spirithold. During his whole life the African was dependent upon the spirits of the deceased, and now he himself will become such a spirit. The relationship between the African and the spirit of death members of his family or of ancestors was extremely important in his society, and because of this reason many songs were and are used in the ancestral cult. These songs provide the motivating force for these ancestral songs and their rituals. The death man or the father had been a prohibiting force upon the individual, and his death has not changed the psychological relationship between the father and his subject - children and family members. The African believe that the father must continue to give his approval and the rituals of the ancestor cult were and are designed to win his benediction and approval. Offerings and sacrifices were made to him before or after singing and dancing had been performed and they rendered certain the will of the sacrifices. There was no question of prayer, as in our religious, with the hope that the wish might be granted by God but there was instead a certainty that the wish would be granted if rituals were properly performed.

The living-dead are bilingual: they speak the language of the spirits and of God, to whom they are drawing nearer ontologically. These are 'spirits' with which African peoples are most concerned: it is through the living-dead that the spirits world becomes personal to men. They are still part of their human families, and people have personal memories of them. The livingdead are still 'people' and have not yet become 'things' or 'spirits.' They return to their human families from time to time, and share meals with them, however symbolically. They know and have interest in what is going on in the household, they inquire about family affairs and may even warn of impending danger. They are the guardians of family affairs, traditions, ethics and activities. Because they are still people, the living-dead are therefore the best group of intermediaries between men and God: they know the needs of men, they have 'recently' been here with men, and at the same time they have full access to the channels of communicating.

When a man dies, therefore, the people have to sing appropriative songs that match the ceremony because if this is not done, it is feared by the relatives that the living-dead would take revenge. This would be in the form of misfortune, especially illness, disturbing frequent appearances of the living-dead or even death. People are thus careful in choosing the songs that they sing during a burial and death cerebrations.

\section{Folk Music Associated with Death Celebrations}

Death celebration among the Grassfields is also known as "second burial." This usually comes up some months or years after a person has passed away. Today, many families in this part of the country prefer to do it soon after the funeral ceremony of a deceased. Like other cultural festivities, music and dance make up an essential part of the activities of each second burial occasion. It is important to note too that in the past, death celebrations were programmed solely in the dry season, a period when there is absence of rain fall that will disrupt the many cultural activities of such a solemn ceremony in the lives of the people.

As discussed earlier, there are many types of dances in the Grassfields chiefdoms and particular dances are performed during specific death celebrations which could be classified under three categories; the death celebration of a commoner, a title holder and a fon. The death celebration of the fon is combined with the enthronement ceremony of a new fon. That is, the death celebration is done first and the enthronement of a new fon is done to succeed the departed.

In the death commemoration of a departed fon, all the traditional dances in the chiefdom have to dance, male and female dance groups as well as the night 'jujus' which are secret. Most male dances or masquerades produce their music using the xylophone and the masquerades dance round these musicians. 


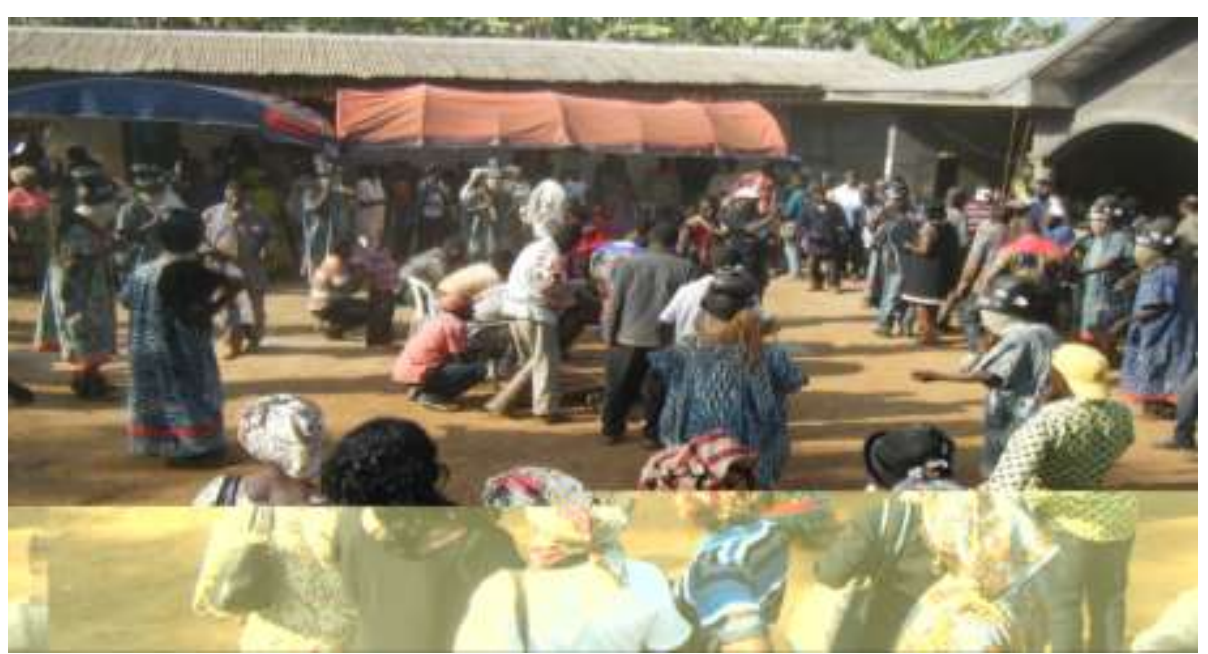

Plate-11: Masquerades dancing in a circular manner. Photo Tikere, 11/11/2019

These male dances may be accompanied by some females who dance at a specific corner and at certain moments of the dance, they produce some extra sounds, they scream. Their screaming adds more beauty to the dance and the music produced with the xylophones. The screaming also signals their presence in the ceremony and a special way to honour the deceased. During the dance, anyone who is moved motivates the musicians, the masquerades and individual dancers financially. This motivation is in cash ranging from one hundred (100) francs to ten thousand $(10,000)$ francs.

\section{Music and Dance during the Death Celebration of a Commoner}

A commoner is anyone in the society who does not have a title and because of this; he comes at the bottom of the social strata of the society. Due to his social status, his death celebration is ordinary. Mostly profane masquerades (mukum) dance with many of them coming out in the day. But in some Grassfields chiefdoms like in Bambui regardless of the status of the deceased, it is the kwifon that opens the ceremony. The palace is duly informed of the date and on the eve of the occasion kwifon goes to the compound at night and opens the celebration. After the official opening by this secret society, the other mukum are free to display, the following day beginning with masquerades and some of them use xylophones.

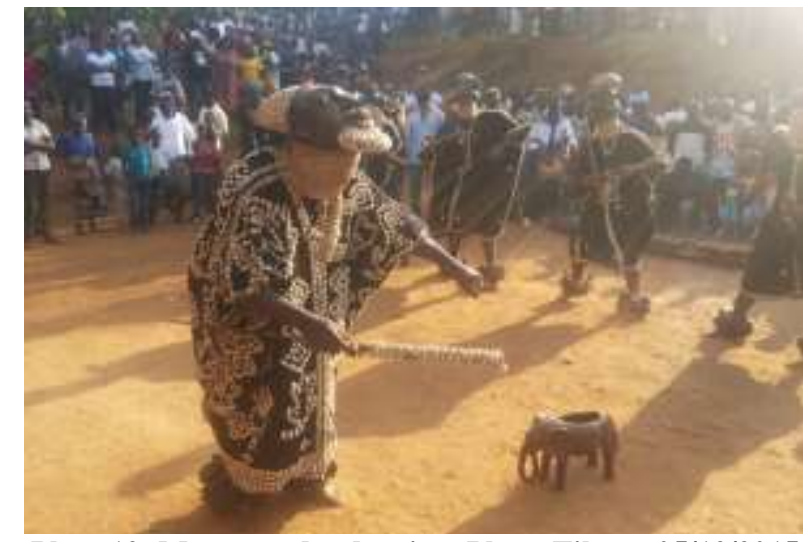

Plate-12: Masquerades dancing. Photo Tikere, 05/12/2015

Dancing often last for two days, on the first day, only male mukum or masquerades perform while on the second day, female dances are on display. If the deceased whose second burial is being done is from a large family, there is a program for dancing such that each dance group perform for a specific length of time. This is so because each family member and in-laws in certain chiefdoms have to present a 'dance'. Such dances can be invited from within or without the chiefdom. Some of such dances may include the njang dance, the $n d o n g$ dance, the samba dance among others.

In a compound where there are xylophones, the children in such a compound spend time from time to time playing them. This gives them the opportunity to master how to play the xylophones. To this effect, whenever this musical instrument has to be used in a ceremony these children will be used. As already mentioned above, xylophones are used mostly by traditional dances and these dances are usually invited to take part in ceremonies such as death celebrations. 
Each time a dance group is invited those who belong to this group; the musicians and dancers have to rehearse for one week to perfect every domain of the dance. During this period, only those who have mastery in playing the xylophones, the drums, the rattles and dancing are retained.

\section{The use of the xylophone in Education}

Many music educators use xylophones as a classroom resource to assist children's musical development. One method noted for its use of xylophones is Orff-Schulwerk, which combines the use of instruments, movement, singing and speech to develop children's musical abilities. Xylophones used in American general music classrooms are smaller, at about $1 \frac{1 / 2}{2}$ octaves, than the $2 \frac{1}{2}$ or more octave range of performance xylophones. The bass xylophone ranges are written from middle $\mathrm{C}$ to $\mathrm{A}$ an octave higher but sound one octave lower than written. The alto ranges are written from middle $\mathrm{C}$ to $\mathrm{A}$ an octave higher and sound as written. The soprano ranges are written from middle $\mathrm{C}$ to $\mathrm{A}$ an octave higher but sound one octave higher than written.

\section{The Xylophone in the Face of Modernity}

The xylophone like any aspect of arts or culture is tantamount to change. But the changes recorded in the xylophone are mostly in the domain of production (raw materials used, tools used, those who were engaged in the production), ownership and usage. In the past, this musical instrument was produced only with the umbrella tree, a tree with white and soft wood easy to cut and carve. Although xylophone bars produced from this wood had high pitch, the frequent use of this wood may have been because of it was soft wood and easy to carve. Today, this invaluable musical instrument is produced from several tree types both soft and hard. This explains why today trees such as camwood, eucalyptus, etc. are used. Those who use these hard woods explain that they (the hard wood) are durable and resistant to insect bite. But the pitch of hard wood is not as high as that of wood from the umbrella tree and other soft and white woods.

The modification is not only in the type of wood used in their manufacture and sizes, but the xylophones are fashioned in different ways. They are put in small boxes (see plate ... below) with smaller xylophones and many of them held together with the aid of strings.

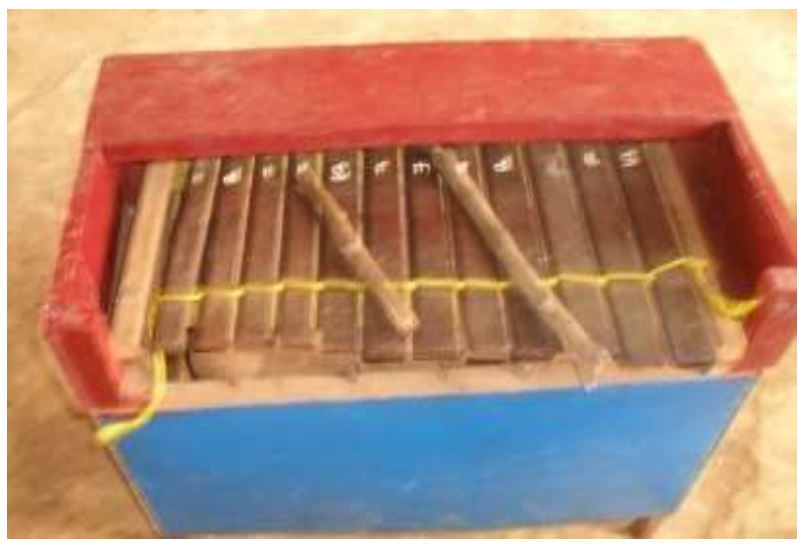

Plate-13: Xylophones build in a box. Photo Tikere, 11/12/2012

There is yet another type that is produced in a way that the player can hang on his waist and played without any difficulty, without having to bend down.

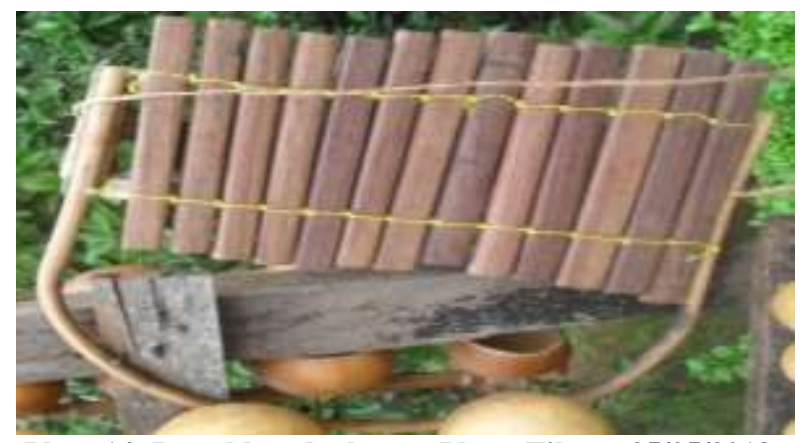

Plate-14: Portable xylophones. Photo Tikere, 25/05/2018

The majority of sacred societies among the Grassfields chiefdoms use the traditional xylophones. These xylophones were placed on plantain or banana stems and such banana stems were obtained in the compound that was hosting the ceremony, this was because the plantain stems are very heavy. Some producers found out that these banana stems were too heavy to be transported from one place to another so they decided to produce non-natural stems from blocks of planks. Some soft material is fixed on the planks so that when hit, the bar of xylophones should produce high sound (see plates below). 


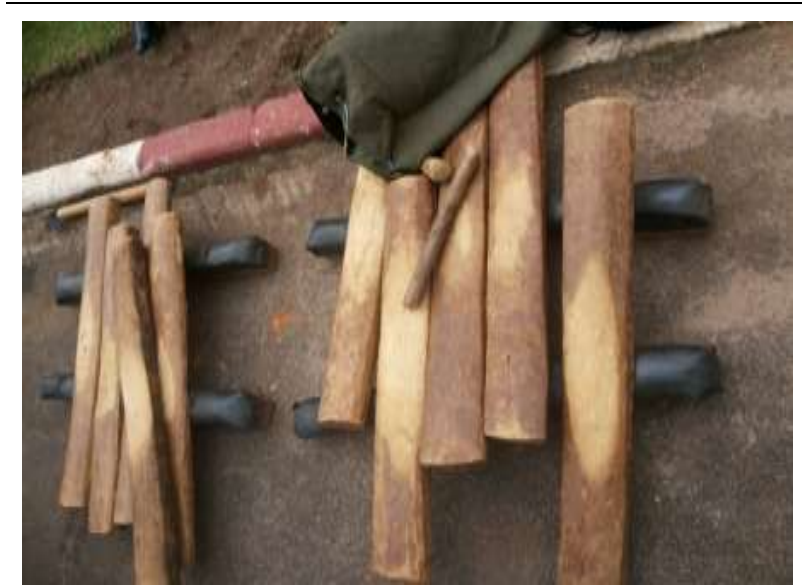

Plate-15: Xylophones laid on plank supports. Photo Tikere, 11/05/2016

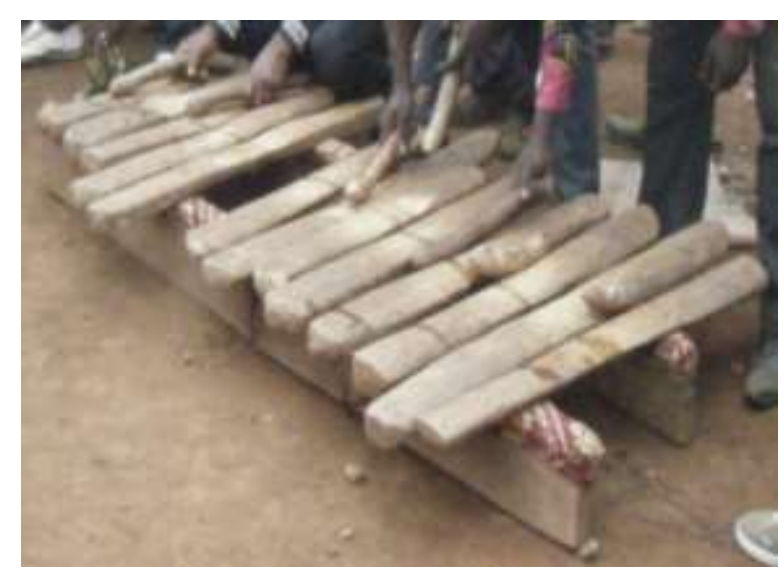

Plate-16: Xylophones laid on plank supports. Photo Tikere, 11/05/2016

Playing xylophones placed either on banana stems or the artificial planks meant that those who were playing this instrument either had to bend for as long as the music had to last or sit on chairs for older people.

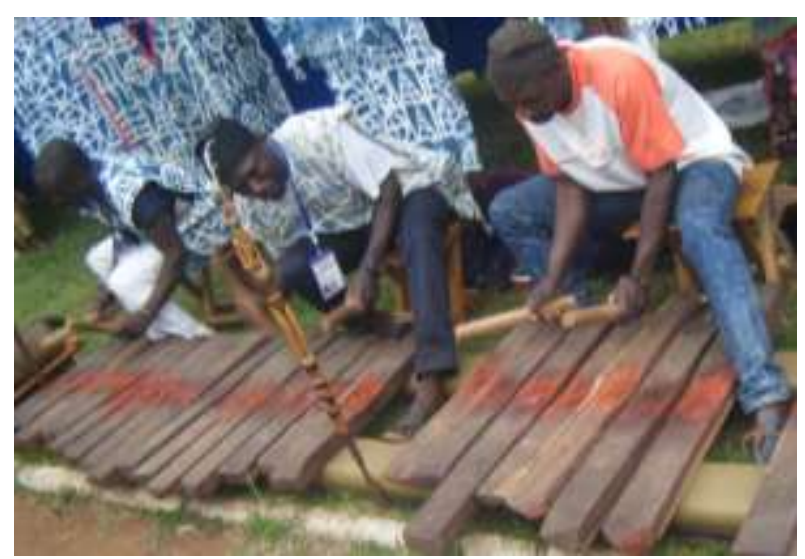

Plate-17: Musicians sitting on chairs before playing the xylophones. Photo Tikere, 11/08/2016
This was really challenging as many of the dances could last for between twenty and thirty minutes. To handle this problem, others decided to build a frame on which to place the bars of xylophones. The stands are either made of plank or iron rods.

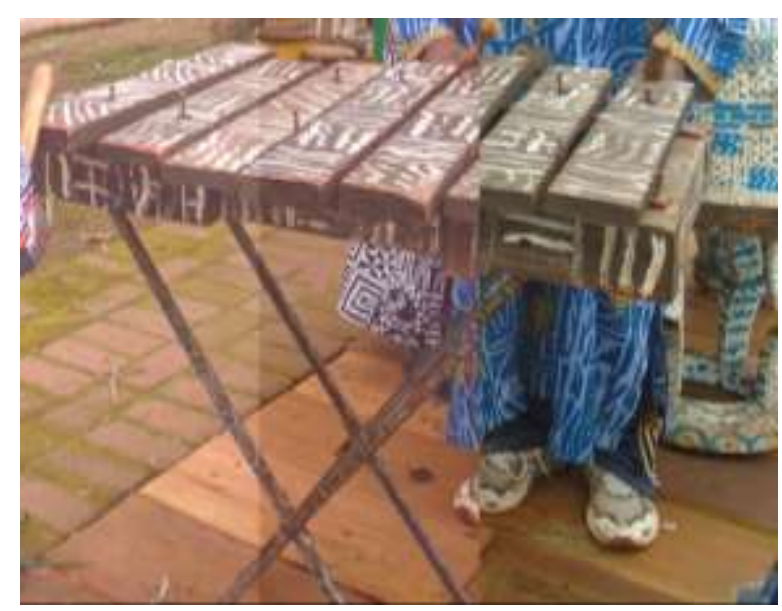

Plate-18: Xylophones placed on a stand. Photo Tikere, 11/08/2016

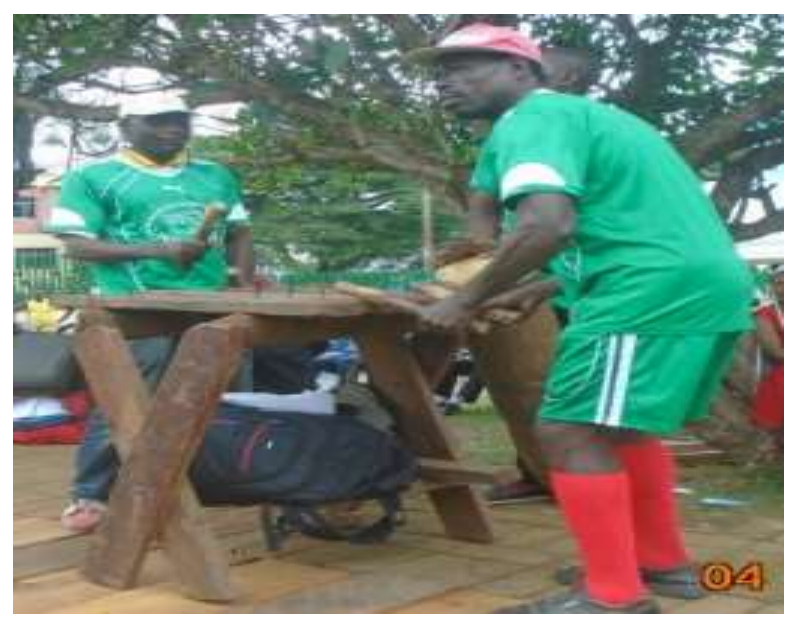

Plate-19: Xylophones placed on a stand. Photo Tikere, 11/08/2016

Churches build their own xylophones in the form of boxes and those who play them sit on low chairs. This very invaluable traditional musical instrument is used in churches to produce praise or worship music aimed at worshiping God. 


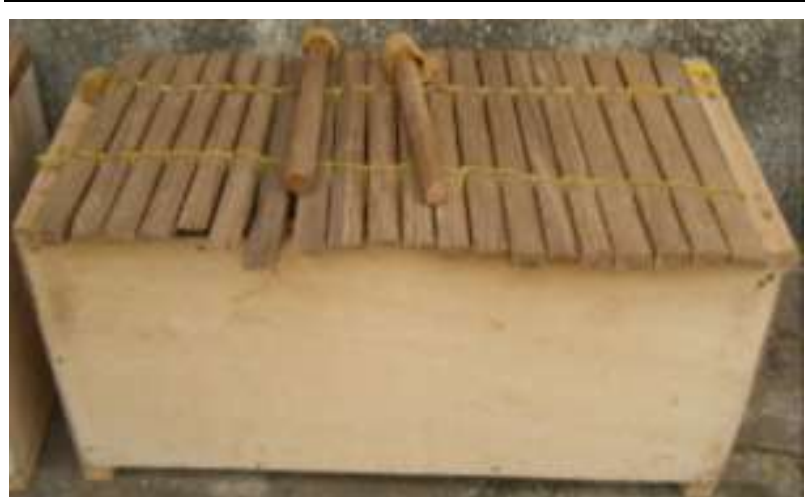

Plate-20: Xylophones used in the church. Photo Tikere, 21/09/2019

The Christian mission: the Basel and Catholic missions have great consequences on the transformation (the production and the use of the xylophones. The music of the Grassfields like that of many parts of Africa can never be the same since the introduction of Christianity. Christian missionaries in general up to present day, have been culpably ignorant of indigenous African religious. In attempting to underline the religious, they have attacked the music, songs and dances which gave expression to spiritual ideas in the often mistaken belief that they were not glorifying God. In the same light, Paden and Soja [3] assert that there have also been iconoclastic movements of nonChristians-type the Atinga cult for example, in 1951 that was responsible for the destruction of sculptures on a measures scale throughout the south western Yoruba land in an attempt to root out witchcraft and sorcery. But Emile Dukheim (1912/1961) points out that all systems of belief, regardless of specific form or content ... have the same objective significance and fulfil the same function everywhere ... there are no religions that are false [4, 5]. All are true in their own fashion; all answer, though in different ways, to the given conditions of human existence. Religious beliefs and practices provide the comfort and reassurance that comes of having some way to explain and cope with the troubles (sickness, hunger, cold, death) and uncertainties of living. Religious beliefs are important in any culture as powerful support for the things people believe they should or should not do and as explanations for these customs.

The majority of producers of xylophones today especially the youngsters, like most artists in this area, have little real connection with culture. In school or in church, they were and are taught to reject their music and dance which is a very important part of their culture as evil. Their literacy has thus created a barrier between them and the guardians of traditions. They belong to a generation that lives in different houses, wear different cloths and even believe in different gods. They see no reason what so ever to continue with the tradition of their fathers, they are making an attempt to produce something new or different. More so, those who produce this musical instrument today finds himself between two distinct groups or cultures; a modern style and a traditional fashion. Modern style may require him to be exotic and someone who wants to recognise in his work clever adaptations of traditional models (cultural hybridity or 'metisage'). And on the other hand traditional style requires him to produce in the style of his forefathers. The manner his father had left behind, the traditional fashion of the chiefdom. Many of them would not want to recognise any lasting value in traditional style.

In the past, xylophones were placed on banana stems so that when stroke, the sound should resonate and each time they were in use, the services of two, three or even four persons were required depending on the number of sets of xylophones to help arrange them from time to time as they are being hit. Today, Some people bore holes at the edges of each xylophone to permit them use pins made of spokes of umbrella to pin them on the banana or plantain stems so that when stroke, they should not move.

Among the fang-Betis of the South and centre Region of Cameroon xylophones are built in a way that they can be carried about a single person. Calabashes are fixed under the xylophones to provide high pitch. These xylophones are attached to a wooden frame on which some soft material has been tied with a nylon rope. The function of the rope is to hold the xylophones firm to the frame.

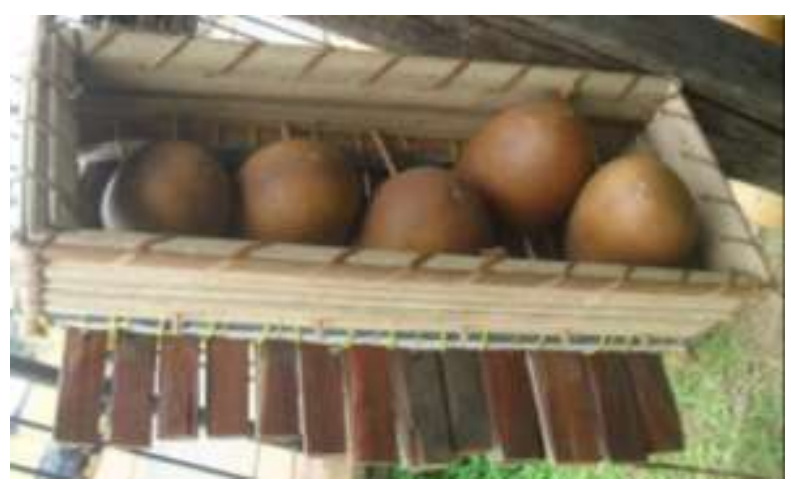

Plate-21: Calabashes used on xylophones, 25/05/2018

For easy identification, xylophones which are not attached to the plank frame, are numbered starting 
from number 1 up to 10 or 12 depending on the number of bars.

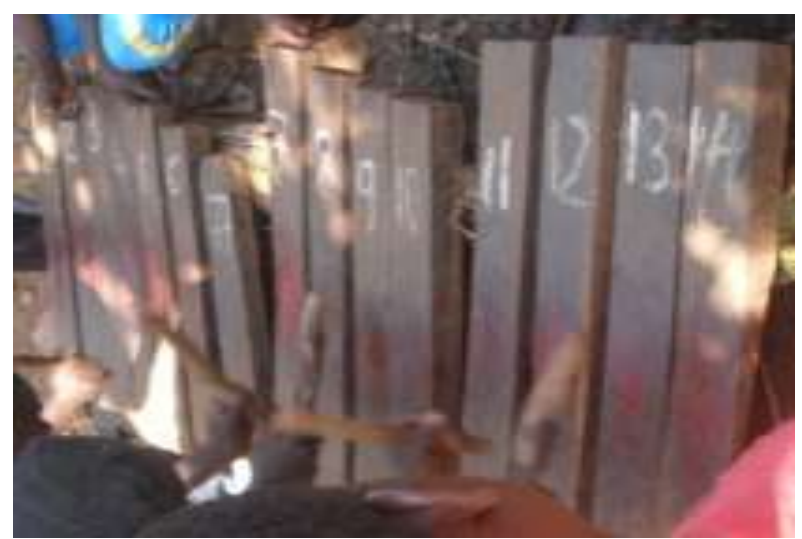

Plate-22: Xylophones bearing numbers. Photo Tikere, 11/05/2017

Some of the xylophones are painted with some symbolic motifs as can be seen in the plate below. These xylophones portray the owner. They are owned by a royalty or a royal dance. This is because the emblematic motifs represented on them are used only by the fons, princes, princess and some notables among the Grassfielders.

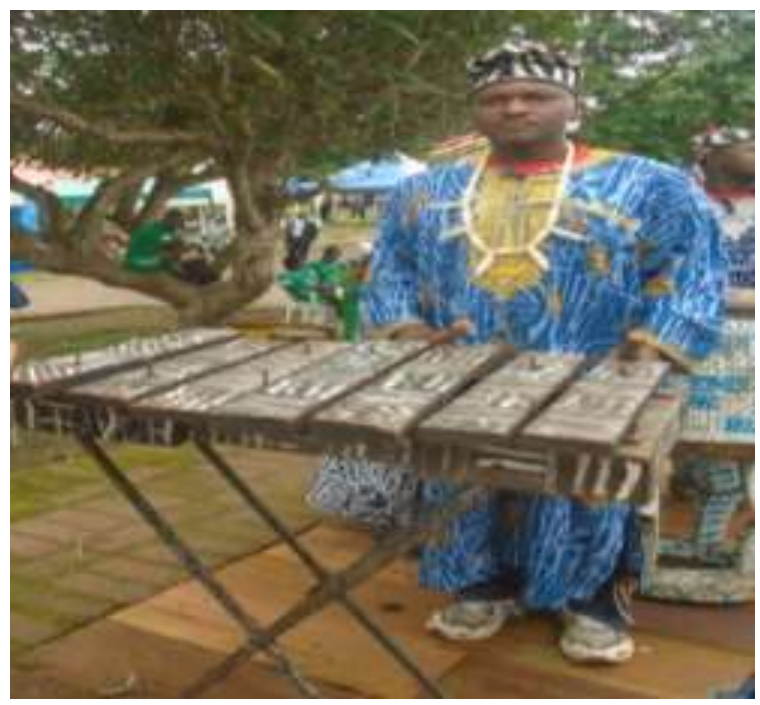

Plate-23: Xylophones painted with emblematic designs. Photo Tikere, 11/08/2016

\section{Ownership of xylophones (masquerades)}

In pre-colonial Grassfields, only the regulatory and sacred societies and notables had the prerogative to own masquerades. All the activities of music and dancing in many Grassfields chiefdoms were controlled by the above mentioned bodies. But when the Grassfields came into contact with the external world, the concept of music and dance changed especially as traditional dance owners were valued more than the others. Apart from the prestige that dance groups brought to their owners, it was also a good source of income. Individuals who were neither princes nor notables could go to the palace to ask for the permission to create a masquerade 'juju'. Important to note again is the fact that majority of these masquerades used the xylophones to produce their music.

As a conclusion, both sacred and profane societies use the xylophone. In pre-colonial Grassfields, xylophones were owned and used only by sacred societies and notables who had masquerades. These xylophones were produced in the tribal style. But today, xylophones are owned and used by jut anyone who has money to create a traditional dance. This musical instrument is equally used in the churches to produce music to praise the Lord. Xylophones therefore, play a very important part in the lives of the Grassfields people. They are used in socio-religious ceremonies to entertain as well as to honour the departed.

\section{REFERENCES}

1. Ben-Amos, P. (1989). African visual arts from a social perspective. African Studies Review, 32(2), 1-53. www.curriulumvisions.com $>$ art $>$ xylophone

2. Segy, L. (1953). Toward a New Historical Concept on Negro Africa. The Journal of Negro History, 38(1), 27-40.

3. Paden, J. N., \& Soja, E. W. (1970). The African Experience.

4. Durkheim, É. (1912). Le problème religieux et la dualité de la nature humaine.

5. Durkheim, E. (1961). Moral education (EK Wilson \& H. Schnurer, Trans.). Glencoe, IL: Free Press.(Original work published 1925).

Cite This Article: Exodus Tikere Moffor (2021). The Dynamics of the Xylophones in Cameroon Grassfields Arts. EAS J Humanit Cult Stud, 3(2), 86-96. 